\title{
O ENDIVIDAMENTO DA SOCIEDADE BRASILEIRA E AS RELAÇÕES OBRIGACIONAIS A PARTIR DA OBRA O MERCADOR DE VENEZA DE W. SHAKESPEARE
}

\author{
Gizelda Rodrigues de Araújo ${ }^{1}$ \\ Émerson Clemente Araújo ${ }^{2}$ \\ Franciele de Paiva Gama ${ }^{3}$ \\ João Henrique Lara Pereira ${ }^{4}$ \\ Caio Vinícius da Silva Vieira ${ }^{5}$
}

RESUMO: O estudo em comento trata-se de uma breve abordagem acerca do Direito das obrigações e do endividamento da sociedade brasileira, através de uma comparação com as evidências históricas presentes na obra O Mercador de Veneza, de William Shakespeare. Destarte, procura-se com o artigo apontar a evolução dos direitos das obrigações por meio da análise dos instrumentos contratuais e, dos endividamentos deles oriundos, os quais se fazem presentes nessa obra clássica e ainda se apresenta como problemática hodierna. Portanto, este trabalho trata-se de uma pesquisa bibliográfica e conta com um arcabouço teórico sólido. Como força motriz o estudo parte das seguintes indagações: Como fica o direito das obrigações mediante a inércia da prestação? O que mudou em termos de relações obrigacionais da antiguidade à atualidade? Por que há um superendividamento do consumidor? $\mathrm{O}$ estudo em comento trata-se de uma breve abordagem sobre o Direito das obrigações e endividamento, destacando as relações obrigacionais presentes na obra de William Shakespeare "O Mercador de Veneza" e evidenciando a evolução dos contratos dos quais originam-se as obrigações. Nesse sentido buscou-se na objetividade do presente texto, utilizar-se da narrativa mencionada para analisar as questões contratuais e o endividamento a partir da obra "O mercador de Veneza" de W. Shakespeare coadunando com o atual Direito Civil. E para tanto, partiu-se da seguinte problemática: Como fica o direito das obrigações mediante o inadimplemento? $\mathrm{E}$ o que mudou em termos de relações obrigacionais da antiguidade `a atualidade? Trata-se de uma pesquisa bibliográfica de cunho qualitativa e contou com o arcabouço teórico de alguns doutrinadores, tais como: William Shakespeare, Maria Helena Diniz, Pablo Stolze, Cristiano Chaves e Tereza negreiros.

\footnotetext{
I Especialista em Métodos e Técnicas de Ensino (Universidade Salgado de Oliveira - UNIVERSO); Especialista em Biologia (Universidade Federal de Lavras -UFLA); Especialista em Gestão Ambiental (Faculdade Serra da Mesa- FASEM); Pós-graduanda em Direito Civil (Pontifícia Universidade Católica PUC-Minas); Graduação em Licenciatura Plena em Pedagogia (Universidade Estadual de Goiás -UEG); Licenciatura Plena em Biologia (Universidade Estadual de Goiás- UEG); Licenciatura Plena em Física (Universidade Federal de Goiás- UFG); Bacharelanda em Direito Universidade Estadual de Goiás-UEG). giseldar@uol.com.br.

${ }^{2}$ Graduando em Direito - UEG

${ }^{3}$ Graduanda em Direito- UEG

${ }_{4}$ Graduado em Engenharia Civil; Graduando em Direito pela UEG; Pós-graduado em Docência do Ensino Superior pela UNOPAR e Pós-graduado em Direito Civil-Teoria Geral e Contratos pela Faculdade Metropolitana do Estado de São Paulo.

5 Graduando em Direito - UEG
} 
Palavras-chave: O Mercador de Veneza. Direito das Obrigações. Superendividamento.

ABSTRACT: The study in question is a brief approach about the law of obligations and indebtedness of Brazilian society, through a comparison with the historical evidence present in the work O Mercador de Veneza, by William Shakespeare. Thus, the article seeks to point out the evolution of the rights of obligations through the analysis of contractual instruments and the indebtedness arising from them, which are present in this classic work and which still presents itself as a problem today. Therefore, this work is a bibliographic research and has a solid theoretical framework. As a driving force the study starts from the following questions: How is the law of obligations due to the inertia of the provision? What has changed in terms of mandatory relations from antiquity to the present? Why is there a consumer over-indebtedness? The study in question is a brief approach to the Law of obligations and indebtedness, standing out as obligatory relationships present in William Shakespeare's work "The Merchant of Venice" and evidencing an evolution of the contracts from which they originate as obligations. In this sense, the objectivity of this text was sought to use the aforementioned narrative to analyze contractual issues and indebtedness from the work "The Merchant of Venice" by W. Shakespeare, in line with current Civil Law. And for that, the following problematic was started: How is the right to obligations upon default? And what has changed in terms of obligatory relationships from antiquity to today? It is a bibliographical research of qualitative nature and counted on the theoretical framework of some scholars, such as: William Shakespeare, Maria Helena Diniz, Pablo Stolze, Cristiano Chaves and Tereza negreiros.

Keywords: The Merchant of Veneza. Right of obligations. Over-indebtedness.

\section{INTRODUÇÃO}

O artigo traz uma reflexão acerca do direito das obrigações, relacionando-o com os fatos narrados no livro o Mercador de Veneza, escrito no século XVI pelo ilustre dramaturgo inglês William Shakespeare. $\mathrm{Na}$ obra, o autor mostra que as relações obrigacionais mediante contrato, naquele contexto, estavam sob a antiga máxima do Direito romano, a de que Pacta sunt servanda (os pactos devem ser observados), esse princípio dizia que as cláusulas e pactos contidos nas relações obrigacionais são expressões do direito entre as partes e o não cumprimento das obrigações, implica em quebra do que foi pactuado.

Desse modo, o princípio da Pacta sunt servanda privilegiava a autonomia da vontade e a segurança jurídica, pois aquilo que foi firmado pelas partes, a partir de suas próprias vontades, teria de fato de ser concretizado. Contudo, mediante a evolução do Direito Civil Brasileiro, em que pese ainda preconize a autonomia da vontade e a segurança jurídica, a situação fática se alterou significativamente. Hoje o que se presencia é a dificuldade ou 
inviabilidade do adimplemento pelo polo passivo da relação obrigacional, por tornar-se a prestação excessivamente onerosa.

Portanto, o que se evidencia é que o princípio da Pacta sunt servanda, não obstante ao propósito da segurança jurídica, tem sido utilizado como ferramenta legitimadora para uma nova forma de escravidão, aquela que torna o polo passivo da relação obrigacional um verdadeiro "escravo moderno" das dívidasPosto isso, ratifica-se a relevância da presente pesquisa para que se torne clara a situação que vivem as famílias brasileiras endividadas pela concessão de crédito, a qual gera obrigações que se alastram durante toda a vida do indivíduo, trazendo por consequência eventos que podem afetar a dignidade humana

Para tanto, o estudo objetiva apontar a evolução dos direitos das obrigações por meio da análise dos instrumentos contratuais e, dos endividamentos deles oriundos, os quais se fazem presentes nessa obra clássica e ainda se apresenta como problemática hodierna, partindo das seguintes indagações: Como fica o direito das obrigações mediante a inércia da prestação? $\mathrm{O}$ que mudou em termos de relações obrigacionais da antiguidade à atualidade? Por que há um superendividamento do consumidor?

Dessa forma, o referido trabalho vem abordar a problemática do superendividamento, o que pode afetar a dignidade da pessoa humana.

\section{O MERCADOR DE VENEZA E O DIREITO}

A história da obra O Mercador de Veneza, de William Shakespeare, se passa no antigo cenário jurídico europeu, e apresenta uma trama fictícia em volta de um drama, contudo, a obra traz também em seu enredo um conteúdo jurídico, sobretudo no que diz respeito às relações obrigacionais. Portanto, o trabalho ora apresentado pretende dar ênfase a esses elementos jurídicos presentes nessa obra.

\section{I RESUMO DA OBRA “O MERCADOR DE VENEZA”}

A trama de O Mercador de Veneza, se dá no século XIV, na cidade de Veneza, considerada nessa época, uma das cidades mais próspera do mundo, graças ao comércio.

O Mercador de Veneza começa com os problemas de Bassânio, um jovem de origem nobre, porém sem muito patrimônio, o qual desejava conquistar e casar-se com a herdeira Pórcia. E para tanto, pedira ajuda a seu amigo Antônio, rico comerciante de Veneza. Mas, 
ao solicitar empréstimo a Antônio, este lhe respondeu que todo seu dinheiro estava comprometido, uma vez que seus navios e bens estavam no mar, mas que se Bassânio conseguisse um empréstimo com outra pessoa, ele seria o fiador.

Depois de consultar alguns amigos, Bassânio encontrou-se com Shylock, antigo agiota de Veneza, conhecido por sua gentileza e por sua eficiência nos negócios, Bassânio o interpelou na saída do mercado e perguntou-lhe se podia financiar o valor de que necessitava: exatamente três mil ducados, em três meses e Antônio como fiador. (SHAKESPEARE, 2008).

Ocorre que Shylock era judeu e fora muito ofendido por Antônio devido ao antissemitismo ${ }^{6}$ em outras ocasiões, agora estava à espera de uma oportunidade para se vingar do mesmo. (SHAKESPEARE, 2008). À época existia o empréstimo denominado "usura", que se baseava em um percentual exorbitante de juros, assim, o agiota Shylock, não exitou em conceder o empréstimo a Antonio, encontrando assim a oportunidade perfeita para iniciar sua vingança (SHAKESPEARE, 2008).

Shylock, ao realizar os trâmites do empréstimo, impõe uma condição absurda: "se o empréstimo não for pago em três meses, Antonio ficará obrigado a pagar com um pedaço da sua própria carne, contendo exatos I (uma) libra de carne ${ }^{7}$, como garantia”. Neste momento desenvolve-se uma relação inter partes (entre as partes), Antonio (sujeito passivo) e Shylock (sujeito ativo), é dizer, nasce uma obrigação entre eles (SHAKESPEARE, 2008).

Dessa perspectiva Trindade faz a seguinte ponderação,

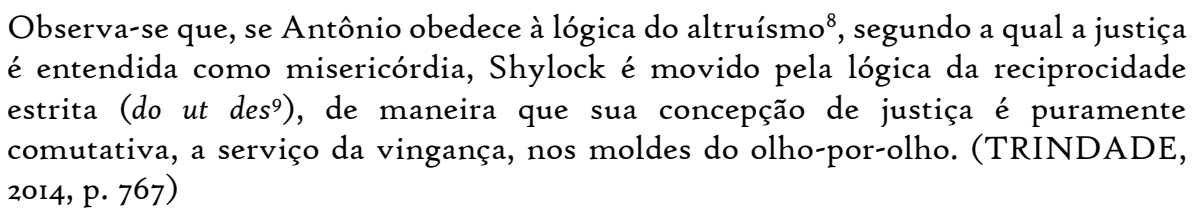

Contudo, mesmo sem desconfiar ou perceber as reais pretensões de Shylock, Antonio, persiste e segue adiante para firmar contrato, com o intuito de satisfazer a felicidade de seu

\footnotetext{
${ }^{6}$ Antissemitismo é o ódio e preconceito contra o povo judeu e sua cultura, ou seja, uma forma de xenofobismo 77 Uma libra de carne, corresponde a quase meio quilograma de carne., É a unidade de massa equivalente a exatamente 0,45359237 quilogramas (ou 453,59237 gramas).

8 segundo o pensamento de Comte 1798-1857, tendência ou inclinação de natureza instintiva que incita o ser humano à preocupação com o outro e que, não obstante sua atuação espontânea, deve ser aprimorada pela educação positivista, evitando-se assim a ação antagônica dos instintos naturais do egoísmo..amor desinteressado ao próximo; filantropia, abnegação

9 (locução latina que significa "dou para que [me] dês"). locução.
} 
amigo Bassânio (SHAKESPEARE, 2002). Bassânio não deseja pegar o dinheiro nessas condições, mas Antônio consente, firma o pacto e registra em cartório.

Bassânio alcança seu objetivo de conquistar Pórcia, mas Antônio não consegue quitar sua dívida adquirida de Bassânio. Antônio descobre que seus navios se perderam em altomar. Essa notícia de que seus navios naufragaram, deixa Antonio em uma situação complicada, sendo levado à Corte de Veneza para definir se o contrato será mesmo executado.

Agora, ele não tem mais dinheiro para pagar Shylock, que resolve vingar-se. Antônio é preso e levado ao tribunal. Bassânio, após seu casamento com Pórcia, descobre o problema em que seu amigo se encontra e parte imediatamente para Veneza a fim de encontrar Shylock e lhe oferecer o dobro da quantia emprestada.

Mas, como já havia passado do dia combinado, Shylock, querendo vingar-se de Antônio, recusa a oferta e insistia na sua garantia - uma libra de carne do corpo de Antônio, de qualquer parte que ele desejasse tirar.

Acontece que Pórcia, esposa de Bassânio, disfarçada de juiz convidado para resolver a situação, apresenta a seguinte solução: "O contrato afirma expressamente que somente uma libra de carne deveria ser retirada de Antonio, nem mais nem menos. e assevera que no mesmo contrato não lhe dá o direito a uma só gota de sangue”. (SHAKESPEARE, 2008).

Pórcia acrescenta ainda que a Lei de Veneza é muito clara:” Se pingar uma só gota de sangue cristão, perderá todo seu patrimônio, que será confiscado pelo Estado”. Assim, Pórcia, através de um jogo de interpretação consegue reverter a situação, onde Antônio se livra de sua pena, e Shylock ainda é punido e humilhado outra vez: condenado por dolo, perde parte de seus bens e é obrigado a tornar-se cristão.

\subsection{AS RELAÇÕES OBRIGACIONAIS NA OBRA “O MERCADOR DE VENEZA E NO ATUAL DIREITO CIVIL}

Embora de cunho literário, a obra shakespeariana O Mercador de Veneza constitui uma fonte rica de informação para se pensar o Direito, cuja é possível extrair conhecimentos acerca do universo das obrigações, assunto este importante no Direito Civil. O mercador de Veneza é, além de um clássico da literatura, uma verdadeira aula, que permite o leitor 
(mesmo o mais leigo em Direito) a adentrar no universo das obrigações e das relações obrigacionais.

De acordo com Gagliano (2019), o Direito das obrigações quase não sofre mudanças, daí a possibilidade de uma obra que se passa em 1596, de origem romana, assim como o direito brasileiro, conseguir representar sem grandes discrepâncias o funcionamento do direito das obrigações hodierno.

O Direito das obrigações é o mais lógico de todos os ramos do Direito Civil, mas é também o mais refratário às mudanças. Vale dizer que embora não seja imutável, sofre bem menos a interferência da alteração de valores e hábitos sociais, se comparado, por exemplo, com o Direito de Família. (GAGLIANO, 2019, p. 49)

Segundo Diniz, (2017, p. 2), tem-se que “[...] o direito de forma geral, e por óbvio, o direito das obrigações, é mutável de acordo com as normas sociais de cada época. Porém, nem tudo muda, e é possível nos dias modernos perceber normas e influências criadas num passado distante".

Nos tópicos anteriores, vimos um resumo do enredo da obra e, agora, munidos de tais informações, partimos para as reflexões acerca das obrigações propriamente e das relações obrigacionais estabelecidas entre os personagens. A priori, a indagação que surge de maneira instantânea está relacionada à cláusula abusiva prevista no contrato firmado entre Shylock e Antônio. Seria possível que, caso não adimplida a obrigação de pagar, executarse-ia o mesmo com o pedaço de qualquer parte do corpo de Antônio? Não seria esta cláusula ilegal, visto que coloca em risco a integridade física de uma das partes?

É sabido que o contrato é regido pela manifestação da vontade - que deve ser livre e de boa fé, frise-se - que decorre do princípio da autonomia privada. A exteriorização da vontade de um ou mais sujeitos é o elemento que concretiza o contrato, criando assim um vínculo jurídico e, consequentemente, obrigações entre os envolvidos. Nesse sentido, não há que se falar que houve um vício no negócio jurídico, analisando o aspecto da volição, uma vez que esta é expressa consensualmente pelos personagens, o que nos termos do direito civilista atual seria perfeitamente validado.

Ainda na análise do elemento volitivo, no momento em que Shylock impõe a condição de que Antônio pague em dinheiro o empréstimo de três(03) mil ducados dentro do prazo de três (03) meses e exige ainda que, caso não adimplida esta obrigação, Antônio a faça mediante a entrega de um pedaço de sua própria carne, ambos assumem suas obrigações contratuais e concordam até mesmo com a cláusula abusiva, que embora para os tempos 
atuais configurar-se-ia ilegal, passível de anulação, na época em que se passa o drama, seria perfeitamente executável, haja vista que justiça e vingança privada se confundiam.

No momento em que Shylock, contratado, e Antônio, contratante, assumem suas obrigações contratuais, quais sejam, dar dinheiro de um lado e de outro pagar, nasce ali uma relação inter partes e estes ficam ligados a partir de então por um vínculo jurídico, que se desfaria apenas quando do adimplemento das obrigações de ambos. Fato é que, embora enxerguemos a abusividade e onerosidade da cláusula contratual imposta por Shylock a Antônio, situações de desequilíbrio como estas, ainda hoje são objetos de discussão e até mesmo de demandas judiciais nos tribunais.

Como já dissemos nos parágrafos iniciais, um dos elementos indispensáveis na manifestação da vontade é a boa fé e, nesse sentido, não se pode dizer que a mesma está presente quanto a Shylock, visto que o mesmo cria uma cláusula absurda motivada por um sentimento pessoal e oculto de vingança com relação a Antônio. Trazendo tal questão à baila e com base na legislação civilista contemporânea, seria possível questionar o cumprimento da obrigação imposta a ele por Shylock, em decorrência dessa má fé oculta, ainda que nos negócios jurídicos a orientação é pela conservação do mesmo.

Quando Antônio percebe a incapacidade de cumprir com a obrigação por ele assumida, uma vez que seus negócios entram em ruína, recusa-se a adimpli-la. Eis que Pórcia se passa por juíza e utiliza-se de um truque hermenêutico durante o julgamento para ajudar o amigo a escapar da obrigação presente na cláusula do contrato, que lhe custaria a própria carne. A mesma decide que Shylock poderia executar a obrigação que impôs a Antônio, desde que para isso não derramasse uma gota de sangue do mesmo, o que seria impossível.

O desfecho como vemos foi feliz para Antônio, ainda que naquela época os contratos fossem regidos pelo princípio pacta sunt servanda, baseado na liberdade contratual das partes e na obrigatoriedade de cumprimento, sem qualquer interferência do Estado veneziano, o que seria praticamente incontornável para Antônio, não fosse a execução da cláusula alcançada por repercussões na esfera penal quanto a Shylock.

Evidentemente, trazendo a discussão feita até aqui para os dias atuais, sob a ótica do direito civil contemporâneo, essa obrigação da cláusula seria completamente nula, dada não só sua excessiva onerosidade, mas principalmente por colidir frontalmente com o princípio da dignidade da pessoa humana, uma vez que sua execução causaria lesões corporais e perigo 
à vida de Antônio, o que superaria o princípio da obrigatoriedade de cumprimento do contrato.

Hoje, o próprio Estado criou limites na legislação para diminuir a liberdade dos sujeitos quanto aos contratos justamente no intento de coibir a presença de cláusulas abusivas e onerosas que acabam por desembocar em demandas judiciais.

Assim, todos os aspectos que envolvem o contrato $e$ as obrigações nele compreendidas devem estar em consonância com as leis e os princípios do direito civil, impedindo situações de excessiva onerosidade, má-fé e objeto ilícito como observamos na obra em comento.

Por fim, mister faz-se ressaltar a importância do Direito das obrigações nos dias atuais, ante a frequência de relações jurídicas obrigacionais. Maria Helena Diniz em seu livro 2 "Teoria Geral das Obrigações”, afirma que:

\footnotetext{
Deveras, o homem moderno vive numa "sociedade de consumo", onde os bens ou novos produtos da tecnologia moderna lhe são apresentados mediante uma propaganda tão bem elaborada, que o leva a sentir necessidade primária ou voluptuárias nunca antes experimentadas ,como por exemplo, substituir um carro novo, por um "zero $\mathrm{km}$ " que embora supérfluo, viria satisfazer um anseio de status. (DINIZ, 2019, p. 20)
}

Marx, chamou a esse deslumbramento de possuir o novo (a mercadoria) a qualquer custo, como se estivesse enfeitiçado, de "fetiche da mercadoria". Esse consumo, na maioria das vezes desenfreado e inconsciente, gera ao consumidor parcelas e mais parcelas que somadas o impossibilitam de adimpli-las, incorrendo no risco de um superendividamento.

\subsection{SUPERENDIVIDAMENTO DO CONSUMIDOR}

No final do século XVIII e advento do século XIX, deu-se gênese, na Europa, as chamadas revoluções industriais. Movimentos estes que culminaram em um conjunto de mudanças radicais no modo de produção e por consequência no consumo; a partir de então, a sociedade nunca mais seria a mesma.

A primeira etapa da revolução industrial iniciada entre i76o e I860, na Inglaterra, foi apenas o marco inicial desse processo de mudança de paradigmas, sendo sucedida por outras duas etapas que avançaram pelo século $\mathrm{XX}$ e ainda hoje são responsáveis pelas novas relações de consumo.

A principal mudança oriunda deste processo de revoluções foi a substituição do modo 
de trabalho, que antes era centrada na mão de obra artesanal, passando agora ao emprego de máquinas, fator esse que não só alavancou a capacidade de produzir, mas trouxe sequelas, sobretudo, para classe proletária que, agora perde seu valor dada capacidade de produção frente à capacidade das tecnologias implementadas e por consequência, aumento do desemprego, fato que tem como efeito a perda da capacidade financeira de manutenção do mínimo de dignidade humana.

Ao analisarmos os corolários desse processo histórico retratado, é preciso transcender o olhar superficial das relações sociais presentes no século XXI e compreender que essas inovações transformaram até mesmo a compreensão do próprio conceito de "Dignidade Humana", pois, o cenário que a configurava no passado, pode não ser suficiente para garanti-la no presente. Esse fato acontece dado às novas necessidades que surgem na sociedade. Com base nesse dado, as grandes empresas, criam suas campanhas de marketing, muitas vezes confundindo o consumidor, que se vê obrigado a consumir seus produtos, com o propósito de terem sua dignidade evidenciada, vindo assim, a valorizar mais o ter do que o ser.

Para atender às novas demandas criadas pela produção exacerbada, o Brasil, assim como ocorreu na Europa e nos Estados Unidos ao final do século XX, ampliou o acesso ao crédito, sem se preocupar no entanto com a capacidade financeira suficiente para quitação dos empréstimos, bem como para manutenção do suposto novo padrão de vida promovido por este. Assim, houve forte emprego de publicidade, direcionado, em grande escala, sobretudo, àquelas classes mais vulneráveis da população, notadamente os aposentados.

Tais abordagens publicitárias são eivadas de práticas abusivas, uma vez que aproveitam da ignorância ou situação de vulnerabilidade financeira e/ou psicológica do consumidor, ofertando uma solução rápida, que no primeiro momento parece mesmo resolver a problemática enfrentada ou até possibilitar a concretude de algum sonho, porém condicionam o indivíduo em uma prisão financeira que se estende por longos anos, muitas vezes perdurando por toda sua vida, já que a dívida tende a crescer dada a incapacidade de cumprimento do débito e incidência de juros abusivos (que no momento do crédito não são transparecidos de forma devida). Sendo tal prática vedada pelo CDC - artigo 39, inciso IV.

Diante do exposto, verifica-se nesse novo molde de sociedade, predominantemente consumista, é que as instituições financeiras não são guiadas por condutas responsáveis ao 
conceder o crédito, sendo que este se apresenta das mais variadas formas, como o crédito consignado, o cartão de crédito ou até o cheque especial, sem, no entanto, averiguar com a devida cautela a condição do consumidor em honrar com a dívida contraída, fator esse que tem cada vez mais promovido à insolvência do consumidor e até a incapacidade de alcançar o mínimo de dignidade humana.

O plano real implementado em nossa economia no ano de 1994 teve um papel fundamental para essa mudança radical na oferta e procura de créditos, porém suas consequências são variadas, conforme afirma Bertocello:

[...] Com efeito, é inegável que o crédito permite resolver o problema do acesso de muitas famílias a bens que são indicadores de qualidade de vida e até mesmo indispensáveis ao bem-estar mínimo das famílias. Não há economista no mundo que duvide da importância do crédito para gerar crescimento, pois ao propiciar o aumento do consumo, obriga as empresas a produzir em maior escala e a empregar mais, aumentando o poder de compra da população, com melhora no seu nível de vida. (BERTOCELLO; LIMA, 2010, P. 53)

Note que o avanço da inadimplência repercute no setor do consumo, já que a capacidade de aquisição diminui, tendo como desfecho a redução da procura e assim consequentemente a geração de emprego e renda média, sendo que estas últimas implicam no índice do PIB e esse tem reflexo direto no desenvolvimento da sociedade como um todo.

Nessa linha de pensamento, Pereira e Werllerson asseveram:

O tratamento do superendividamento se insere na política mais ampla de proteção jurídica do consumidor, e como tal adota igualmente seus métodos e sua lógica: tratase de fenômenos da sociedade de massas, que afetam não só o interesse individual, mas igualmente o interesse coletivo dos consumidores, e enquanto tal exige ao mesmo tempo medidas de caráter preventivo e medidas de caráter curativo. (PEREIRA, WERLLERSON, 2006, p. 163)

Segundo dados da Pesquisa de Endividamento e Inadimplência do Consumidor (Peic), promovida pela Confederação Nacional do Comércio de Bens, Serviços e Turismo (CNC), o quantitativo de famílias brasileiras que contraíram algum tipo de dívida aumentou de 65,1\% em novembro para 65,6\% em dezembro de 2019, sendo que esse índice é o maior desde janeiro de 2010, sendo cartão de crédito, o principal precursor na contração destas obrigações financeiras, pois este representou percentual de $79,8 \%$ do total destas.

No entanto, estes dados não podem ser tratados como números frios, sob o risco de se esquecer das graves consequências que promovem no âmbito da vida da família, 
sobretudo daquelas de baixa renda que, muitas vezes, terá sua dignidade humana afetada. Sobre o assunto Chaves, Rosenvald e Netto alertam:

[...] o superendividamento representa a ruína e morte civil do consumidor. Tratase da impossibilidade global de o devedor leigo e de boa-fé fazer frente ao conjunto de seus débitos atuais e futuros. A capacidade econômica do consumidor se torna inferior ao montante dos débitos atuais e futuros. A capacidade dos débitos, todos estes contraídos para atender às suas necessidades pessoais, entendendo como "necessidades" tudo aquilo que o mercado induziu o indivíduo a acreditar como essencial, mesmo em se tratando de bens supérfluos na maior parte das vezes. (CHAVES; ROSENVALD; NETTO, 2019, p.245)

Diante desse prisma apresentado, é importante entender as fontes deste superendividamento, pois elas são variadas, podendo ter como causa: a ambição da casa própria ou automóvel; doença de ente familiar, desemprego, estímulo ao consumo promovido pelo governo e empresas de marketing desenfreado, entre outras razões que, uma vez presentes, tendem a motivar à contração de empréstimos e, após este, muitas vezes por falta de educação financeira ou ainda pelos mesmos fatores que levaram à aquisição do crédito, acabam culminando em inadimplência.

O Brasil enfrentou em 2019 uma grave crise econômica. Em 2020 com a pandemia mundial da COVID-ı9, aliada às condutas praticadas pelo governo em suas relações internacionais, bem como a política adotada pelo presidente Bolsonaro, esse cenário se agravou ainda mais. A condução séria da economia de um país é um fator de suma importância, pois suas repercussões são graves e, quase sempre, levam ao aumento da inadimplência, uma vez que a renda per capita diminui, fator que atinge diretamente o consumo e, se há menor consumo, há menor produção, se esta é reduzida por sua vez, haverá maior desemprego.

Os dados socioeconômicos, são sensíveis e, conforme dito anteriormente, não podemos tratá-los como "números frios", pois representam uma cadeia de ações que culminam na insolvência da dignidade humana daqueles que se encontram já em situação de vulnerabilidade.

Assim, diante do panorama enfrentado nos últimos seis anos no Brasil, sobretudo neste ano de 2020, onde, além da crise do mercado financeiro, há aumento exponencial do desemprego (dada necessidade de isolamento como medida essencial no combate à propagação do vírus da COVID) somado ao risco de contração da doença (que obriga à gastos imprevistos), a tendência é de uma curva linear crescente do endividamento das 
famílias brasileiras que, em situação de calamidade, não assistidas de forma devida pelo poder público, contraem créditos para suprir suas necessidades básicas ou ainda para arcar com aquelas já contraídas antes deste período.

Desse modo, em vista dos fatos supramencionados, bem como sua reflexão, é imprescindível ações de governo no sentido de evitar que esse cenário se configure, como políticas públicas, que passam pelo legislativo, criando dispositivos capazes de proibir a prática abusiva de publicidade dos serviços de crédito, bem como assegurar que as instituições financeiras ao realizar a concessão destes serviços melhor avaliem as condições do contrato, de modo a não promover a insolvência do devedor praticando condutas abusivas de juros e taxas. Já ao executivo, se faz mister garantir a eficiente fiscalização das referidas regulações dadas pelo legislativo, criar programas de educação financeira, além de promover, através das instituições financeiras da união (Banco do Brasil e Caixa Econômica), a renegociação das dívidas das famílias que se encontram em situação de insolvência (pois teria capacidade de negociar com as demais instituições valores bem mais baixos de juros e taxas) e dar a estas famílias a possibilidade de refinanciamento, com parcelas que estas consigam honrar, sem haver comprometimento de sua dignidade humana. Só assim será possível amenizar tal problemática.

\subsection{PARADIGMA DA ESSENCIALIDADE}

Chaves, Netto e Rosenvald (2019), sobre materialização dos contratos, afirmam que o contrato, em sua acepção clássica, era a exata tradução de um monismo valorativo e que na medida em que a autonomia da vontade fazia-se absoluta, sem concorrer com outros princípios, o contrato era inserido no plano da liberdade formal, aliada a espontânea submissão do indivíduo à limitação de sua liberdade, desligando-se por completo das condições materiais das partes.

Todavia, com a progressiva transformação contratual, a qual sucumbiu a visão clássica contratualista, em razão da ascensão de questões pautadas no bem-estar social e da adequação do direito civil à principiologia constitucional tornam impraticável a perpetuação de um conceito racional de contrato perspectivado puramente pela individualidade e pela autonomia. E, de maneira a evitar que o contrato se torne um instrumento de opressão e 
para convertê-lo em meio de libertação, será acrescido pelos princípios da boa-fé objetiva, da função social do contrato e do equilíbrio contratual.

Nesse sentido, depreende-se que sobre a égide da solidariedade constitucional à disciplina contratual passa a se ajustar, sob molde harmônico, aos direitos fundamentais.

Este novo modo de ver o contrato é sintetizado por Teresa de Negreiros, a qual conclui que,

a depender da relevância do objeto contratado à satisfação das necessidades existenciais da pessoa humana contratante, a hermenêutica dessa relação jurídica deve ser diferenciada, sob a luz do "paradigma da essencialidade", de modo que o direito dos contratos se curva perante as necessidades humanas fundamentais, a pessoa e a sua dignidade. (2006, apud BASAN, 2016, p. 2I).

Segundo Ribeiro e Steiner (2008, p. 579), o "paradigma da essencialidade, pautado por sua vez na cláusula geral da dignidade da pessoa humana, chega-se à diferenciação dos contratos a partir da classificação de seu objeto como bem útil, supérfluo ou essencial". Continua dizendo que,

a definição da essencialidade dos bens se daria a partir de uma análise casuística, já que não se poderia imaginar que a Lei viesse a definir a partir de incontáveis subjetividades, o que para um seria essencial, e não para o outro. (RIBEIRO e STEINER, 2008. p. 580)

Destarte que a separação entre as relações contratuais patrimoniais das existenciais pautadas na essencialidade do bem torna-se um critério relevante para delimitação da proteção à autonomia privada.

Diante disso, abstrai-se que a partir da classificação dos bens na relação contratual seria determinada a intensidade de proteção do objeto, de modo que quanto maior a essencialidade do bem para à pessoa humana, maior seria à tutela dos direitos fundamentais, enquanto ao revés, figurando no contrato bens supérfluos, maior seria a autonomia privada.

Ressalta-se que apesar da intercessão principiológica constitucional, a qual impôs limites à autonomia privada, não se restringiu a autonomia contratual, como extrai-se do Enunciado $n^{\circ} 23$ do Conselho de Justiça Federal: "A função social do contrato, prevista no art. 42I do novo Código Civil, não elimina o princípio da autonomia contratual, mas atenua ou reduz o alcance desse princípio quando presentes interesses metaindividuais ou interesse individual relativo à dignidade da pessoa humana."

\section{DISCUSSÃO}

Diante das questões elencadas no decorrer do artigo, nota-se que houve uma transformação na perspectiva obrigacional das relações contratuais, de modo que com o 
avanço de pensamentos pautados no bem-estar social e com a imposição do direito privado de avaliar os direitos fundamentais em suas relações, desenrolou-se num afastamento ao rígido modelo contratual apresentado pela obra "Mercador de Veneza" no qual se verifica uma sistemática estabelecida pela autonomia privada das partes, havendo imposição à obrigatoriedade contratual por conta da força de lei dada aos contratos.

Ademais, quando demonstrado os principais marcos que levam ao superendividamento, dentre eles, o consumismo, tornou-se possível verificar a importância do Direito das Obrigações, dado o progressivo aumento das relações jurídicas obrigacionais nos dias atuais.

Posto isso, ratifica-se a relevância da presente pesquisa para que se torne clara a situação que vivem as famílias brasileiras endividadas pela concessão de crédito, a qual gera obrigações que se alastram durante toda a vida do indivíduo, trazendo por consequência eventos que podem afetar a dignidade humana.

\section{CONSIDERAÇÕES FINAIS}

Os contratos sofreram algumas mutações, principalmente no que diz respeito ao grande diferencial do conceito moderno de obrigações, quando comparado com seus antecedentes históricos, deslocando-se o objeto imediato em caso de inadimplemento, da pessoa do devedor para o seu patrimônio ou serviço.

No entanto, embora se verifique que os indivíduos não satisfazem as pretensões das obrigações com seu próprio corpo, ou tenham que trabalhar de graça para quitar uma dívida com seu credor; o que se observa é que os indivíduos das classes menos abastadas têm se tornado verdadeiros "escravos modernos" de dívidas infinitas, devido ao superendividamento provocado pela facilidade ilusória do crédito.

Logo, é fato que a sociedade brasileira tem se tornado cada dia mais endividada, isso se dá pelos atrativos e instrumentos do próprio sistema, que cria e recria ferramentas para manutenção da ordem econômica e das regalias da nova classe burguesa, classe esta que espolia ao máximo a classe trabalhadora, por meio de uma estrutura jurídica que, não se engane, está a serviço do capital.

Observa-se na peça shakespeareana que Shylock exige a aplicação estrita da lei pelo tribunal, nos mostrando que o Direito só apresenta existência efetiva quando se manifesta 
em toda sua complexidade. Todavia, se ainda prevalecesse tal lei das relações contratuais nos dias atuais, em virtude do superendividamento teríamos uma sociedade de mutilados.

\section{REFERÊNCIAS}

BASAN, Arthur Pinheiro. O contrato existencial: análise de decisão judicial que assegura a sua aplicação. Revista Brasileira de Direito Civil, v. 07, 2016.

BRASIL. Constituição da República Federativa do Brasil 1988. Senado Federal. Disponível em: 〈http://www.planalto.gov.br /ccivilo3/constituicao/comstituicao.htm〉 Acessado em: 28 set. 2017〉. Acessado em: 25/04/2020.

BRASIL. Lei no 8.078, de II de setembro de 1990. Dispõe sobre a proteção do consumidor e dá outras providências. Diário Oficial da União, Brasília, DF, ir de set. de 1990. Disponível em: 〈http://www.planalto.gov.br/ccivil_03/leis/18078.htm〉. Acessado em: or/o5/2020.

BRASIL. Medida provisória no 2.172-32, de 23 de agosto de 200I. Estabelece a nulidade das disposições contratuais que menciona e inverte, nas hipóteses que prevê, o ônus da prova nas ações intentadas para sua declaração. Diário Oficial da União, Brasília, DF, 23 ago. 20or. Disponível em: 〈http://www.planalto.gov.br/ccivil_03/MPV/2172-32.htm〉. Acessado em: 01/05/2020.

BERTOCELLO, Karen. LIMA, Clarissa Costa. Explicando o superendividamento em questões: perguntas e respostas. In: BERTOCELLO, Karen. LIMA, Clarissa Costa. MARQUES, Cláudia Lima (Org.). Prevenção e tratamento do superendividamento. Ed. ENDC. 2oı. Cap. 2, p. 39-48.

BERTOCELLO, Karen. LIMA, Clarissa Costa. Tratamento do crédito ao consumo na américa latina e superendividamento. In: In: CAVALLAZZI, Rosângela Lurnadelli. MARQUES, Cláudia Lima (Org.). Direitos do consumidor endividado: superendividamento e crédito. São Paulo. RT, 2006. Cap. 7.p. 191-210.

FARIAS, Cristiano Chaves de; ROSENVALD, Nelson; NETTO, Felipe. Manual de Direito Civil - Volume Único. $4^{\mathrm{a}}$ ed. Salvador: Editora Juspodivm, 2019.

DINIZ, Marco Paulo. Direitos das obrigações: Uma abordagem dos aspectos evolutivos desde o início da humanidade. Revista Boletim Juridico, Disponível em: 28 set. 2017.

DINIZ, Maria Helena. Curso de Direito Civil Brasileiro.Teoria Geral das Obrigações. Vol.oz.Ed. Saraiva. $34^{\text {a }}$ edição. 2019. São Paulo.

Endividamento das Famílias em dezembro é o maior desde 2010, aponta CNC. Valor Econômico. Disponível em: <https://valor.globo.com/brasil/noticia/2020/or/og/endividamento-das-famliasem-dezembro-o-maior-desde-2010-aponta-cnc.ghtml〉. Acesso em: 07/05/2020.

FARIAS, Cristiano Chaves; Netto, Felipe Braga; Rosenvald, Nelson. Manual de Direito Civil. Volume Único. $4^{\text {a }}$ edição. Ed. Juspodivm.2019.

GAGLiAnO, Pablo Stolze;Filho, Pamplona Rodolfo. Novo Curso de Direito Civil. Vol.o2. Obrigações. 20 ${ }^{\underline{a}}$ edição. Editora Saraiva. 2019. São Paulo

GOMES, Orlando. Contratos. I8 ${ }^{\mathrm{a}}$ ed., Rio de Janeiro, Forense, 1998. p. 36. 
I JORNADA DE DIREITO CIVIL. CJF-Enunciados, 2002. Disponível em:< https: // www .cjf . j us.br/enunciados/enunciado/669>. Acesso em: 05/05/2020.

LAKATOS, Eva Maria; MARCONI, Marina de Andrade. Fundamentos de metodologia científica. 5. ed. São Paulo: Atlas, 2003.

NEGREIROS, Teresa. Teoria do contrato: novos paradigmas. 2. ed. Rio de Janeiro: Renovar, 2006.

PEREIRA; WELLERSON. Serviços Bancários e Financiamentos na Europa: as diretivas e normas aplicáveis. 2006.

SHAKESPEARE, William. O Mercador de Veneza. Adaptação: Leonardo Chianca. Editora DCL. $\mathbf{I}^{\mathbf{a}}$ Edição. 2008. São Paulo.

SOUZA FILHO, Luiz Fernando Ferreira de. Pacificação/administração de conflitos sociais e a realização da justiça. Revista EMERJ, Rio de Janeiro, v. 15, n. 59, p. 24-35, 2012. Disponível em: acessado em: 28 set. 2017.

TRINDADE, André Karam. Pórcia e os limites da interpretação do Direito. Novos Estudos Jurídicos, v. 19, n. 3, p. 755-786, 2014.

RIBEIRO, Marcia; STEINER, Renata Carlos. O paradigma da essencialidade nos contratos: recensão da obra de Teresa Negreitos. São Paulo: Revista Direito GV, p. 569-58I, 2008. 